\title{
A TD-DFT investigation of UV spectra of pyranoïdic dyes: A NCM vs PCM comparison
}

\author{
Julien Preat $^{\mathrm{a}, *, 1}$, Pierre-François Loos ${ }^{\mathrm{b}}$, Xavier Assfeld ${ }^{\mathrm{b}}$, Denis Jacquemin ${ }^{\mathrm{a}, 2}$, \\ Eric A. Perpète ${ }^{\text {a }}$ \\ a Laboratoire de Chimie Théorique Appliquée, Facultés Universitaires Notre-Dame de la Paix, rue de Bruxelles, 61, 5000 Namur, Belgium \\ ${ }^{\mathrm{b}}$ Equipe de Chimie et Biochimie Théoriques, UMR CNRS-UHP 7565, Université Henri Poincaré Nancy 1-BP 239, \\ 54506 Vandoeuvre-lès-Nancy Cedex, France
}

Received 22 December 2006; accepted 26 December 2006

Available online 14 January 2007

\begin{abstract}
We report the calculation of the UV spectra of more than 40 substituted coumarins and chromones in solution. In particular, two solvent models are compared, the multipolar expansion model (NCM) developed in Nancy and the PCM scheme developed in Pisa and Napoli. All calculations are carried out at the NCM-TDPBE0/6-311G(2d,2p)//NCM-B3LYP/6-311G(2d,2p) and at the PCMTDDFT/6-311+G(2d,2p)//PCM-DFT/6-311G(2d,2p) levels of theory. For most of the studied coumarin and chromone derivatives, there are at least two allowed excited states corresponding to transitions presenting a strong oscillator strength in the UV region. For the NCM treatment of substituted pyranones, the required accuracy for the design of molecules has been reached (we found a accuracy on the predictive data of $7 \mathrm{~nm} / 0.08 \mathrm{eV}$ for $\lambda_{\max }^{(1)}$ and $9 \mathrm{~nm} / 0.18 \mathrm{eV}$ for $\lambda_{\max }^{(2)}$ ). Compared to PCM values, the NCM formalism provides $\lambda_{\max }^{(1)}$ predictions with equivalent accuracy and reliability. For $\lambda_{\max }^{(2)}$, the importance of diffuse functions is clearly demonstrated.
\end{abstract}

(C) 2007 Elsevier B.V. All rights reserved.

Keywords: Pyranone; Density-functional-theory; UV spectra; Solvent effects; PCM; NCM; SCRF

\section{Introduction}

Modern theoretical methods are now able to predict the properties of chemical systems with almost the same accuracy as experiment, as long as isolated systems are considered. However, solvent effects on the thermodynamics, kinetics and spectroscopic properties of chemical and biological phenomena are often not negligeable. Being able to describe chemical processes in solution using theoretical methods modelling solvent effects, at a level of accuracy comparable to that attainable for isolated systems, is then

\footnotetext{
* Corresponding author. Tel.: +32 081 724568; fax: +32 081724567. E-mail address: julien.preat@fundp.ac.be (J. Preat).

${ }^{1}$ Fellow of the Belgian Fund for the Formation to Research in Industry and Agriculture (FRIA).

${ }^{2}$ Research Associate of the Belgian National Fund for Scientific Research (FNRS).
}

of primary importance. In this scope, computational methods have proven to be very powerful tools for understanding solute-solvent interactions and predicting structures, spectra, as well as reactivity in liquid phase [1]. Modelling the solvent by means of a continuum is particularly attractive, owing to its reduced computational costs with respect to methods explicitly representing the surrounding molecules. In a continuum model, based upon the self-consistent reaction field (SCRF) principle, one directly calculates the ensemble average of solute-solvent interactions at thermal equilibrium $[2,3]$.

Pyranone derivatives that include coumarins and chromones, are built from two fused aromatic cycles, which can easily be functionalized by several side groups. These compounds owe their success to their taylorable properties combined with a high stability. For instance, the coumarin derivatives are of considerable biological and medical interest because they show anticoagulant activity effects, though 
remaining weakly toxic [4]. In physico-chemical applications, their light emission abilities make them the main fluorescent dyes used in paints and inks. Indeed, these dyes often absorbing in the UV region, emit blue-green light, and are known to be efficient fluorescent brighteners [5]. In 1929, Krais treated rayon and flax with an extract composed of husks of horse chestnut to make them water-proof. This extract contained esculin, a fluorescent glucoside now known as 6,7-dihydroxycoumarin. The first industrial optical brightener was methylumbelliferone (4-Me,7-OH coumarin), which is easily obtained from resorcinol (benzene 1,3-diol) and 3-oxobutanoate. In 1999, the World production of fluorescent brighteners amounted to 40,000 tons of active substances [6]. Nowadays, some special fluorescent brighteners are also applied in laser-dye technology and there is a huge interest in the design of new compounds able to emit in the yellowred region of the visible spectrum [7].

This work aims at the comparison of two different SCRF formalisms used in their default implementation: the multipolar expansion method (NCM for nancy continuum model) developed by Rivail and Rinaldi, and the polarizable continuum model (PCM) of Miertus, Scrocco, and Tomasi $[2,3]$. The experimental UV spectrum of pyranoïdic dyes (Fig. 1) in ethanol is used to compare the performance models. In general, when small size solutes are treated quantum mechanically, the cost of a SCRF calculation that includes solvent effects is similar for any model and is only slightly larger than that of the corresponding gas-phase calculation. However, as the size of the system increases, the $C P U$ cost might rapidly be model-dependent. Our initial methodological investigation [8] gathers the comparison of the coumarin spectroscopic properties obtained with both models: more precisely, we investigated the IR spectra and determined the conditions under which the SCRF models can be calibrated to experiment. In a second time, we proposed first insights of the transferability to the UV spectra. In this present work, we extend this analysis to a large set of chromone and coumarin derivatives. The results are used for statistical studies, allowing both a comparison of the two SCRF models, and a confrontation between theoretical and experimental data. This contribution is organized as follows: Section 2 succinctly defines our methodology. Section 3 gathers the comparison of the spectroscopic results obtained with both models. In Section 3.1, we isolate the direct and indirect effects of the SCRF for-

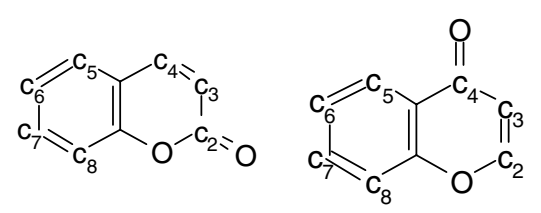

Fig. 1. Sketch of coumarin (left) and chromone (right) with numbering of the substitution positions. malism on the UV spectra. In Section 3.2.1, we present a comparison between the PCM and NCM TD-DFT results. In Section 3.2.2 and 3.2.3, these results are related to experimental data: we test the reliability as well as the predictive abilities of the NCM and PCM models.

\section{Methodology}

In the SCRF methods, one divides the problem into a solute part (the pyranone dye) lying inside a cavity, and a solvent part represented as a structureless material, characterized by its dielectric constant as well as other parameters like the molar volume, the polarizability,... In these methods, the solute charge distribution is represented as a continuous electron density, associated to a fixed nuclear configuration inside the solute cavity. In PCM, one of the most widely used approaches for evaluating bulk solvent effects [9-16], the solvent reaction field is expressed in terms of a set of charges distributed all over the solute cavity surface. These charges are induced by the solute charge distribution, thus expressing the mutual solute-solvent polarization. In this model, the surface charges are obtained by numerically solving the Poisson equation with the IEF (Integral Equation Formalism) code [11,14-16]. In NCM formalism, the solute-solvent interaction energy is evaluated via a multicentric multipolar Taylor expansion of the electrostatic potential $[17,18]$. We refer the reader to Ref. [8] for more details about the NCM procedure. Because we study electronic spectra in this paper, we have selected the non-equilibrium PCM and NCM solutions [9]. PCM and NCM calculations have been performed with the standard Gaussian03 package [19] and the modified Gaussian03 package (SCRFPAC [20]) developed by D. Rinaldi et al., respectively. The comparative study has been built following the two-step methodology:

(1) The standard procedure combined with PCM for the UV spectra evaluation is TD-DFT/6-311+G(2d,2p)// DFT/6-311G(2d,2p) scheme using B3LYP [21,22] for the geometry optimization and PBE0 for the TD calculations [23,24]. In the NCM case, because of SCF cycle divergence when diffuse functions are added, the theoretical level is limited to TD-PBE0/ 6-311G (2d,2p)//B3LYP/6-311G(2d,2p).

(2) The results from both approaches are treated by means of a simple linear regression (SLR) scheme $[25,26]$ that analyzes the relationship between one dependent variable (the experimental value) and one independent variable (theoretical values or properties). The accuracy associated to the regression is measured with the mean average error (MAE), and the level of the prediction accuracy is provided by the standard deviation of the residual (SDR), whereas the prediction reliability is given by the adjusted correlation coefficient (adjusted $R^{2}$ ). 


\section{SCRF formalism effects on UV spectra}

The theoretical $\lambda_{\max }$ reported in the following correspond to the first singlet excited states with dipole-allowed transitions (i.e., nonzero oscillator strength $f$ ) from the ground state. Though we express the excitation energies in $\mathrm{nm}, \mathrm{eV}$ are also used for the statistical treatment. For most of the studied derivatives, there are two allowed states close in energy in the UV/VIS region, characterized by a large transition probability [27-31]. The first absorption band $\left[\lambda_{\max }^{(1)}\right]$ is typically of medium intensity and is observed in the vicinity of $290 \mathrm{~nm}$ (for chromone) and $330 \mathrm{~nm}$ (for coumarin). The second absorption band $\left[\lambda_{\max }^{(2)}\right]$ is observed in the $200 \mathrm{~nm}$ (for chromone) and $300 \mathrm{~nm}$ region (for coumarin). The corresponding excitation processes involve typical $\pi \rightarrow \pi^{*}$ transitions and are related to a charge transfer from the benzenic cycle to the pyranone moiety, but with a larger redistribution of the charges for $\lambda_{\max }^{(2)}[32]$.

\subsection{Direct and indirect effects}

Formally, one can split the solvent effects on the electronic excitation into two components: (i) a modification of the ground-state geometry (indirect component) and (ii) a polarization of the electronic wavefunction, which induces a perturbation of the UV spectra (direct component). The relative weight of the direct and indirect contributions is shown in Tables 1 and 2. More precisely, Table 1 deals with the standard procedure combined with PCM and NCM whereas Table 2 provides the PCM and NCM
Table 2

Direct solvation effects on the calculated $\lambda_{\max }$ (in $\mathrm{nm}$ ) of coumarin derivatives and chromone

\begin{tabular}{|c|c|c|c|c|c|c|}
\hline \multirow[t]{3}{*}{ Substituents } & \multicolumn{6}{|c|}{ Gas Geometry } \\
\hline & \multicolumn{2}{|c|}{ Gas UV } & \multicolumn{2}{|c|}{$\mathrm{PCM}(\mathrm{EtOH}) \mathrm{UV}$} & \multicolumn{2}{|c|}{$\mathrm{NCM}(\mathrm{EtOH}) \mathrm{UV}$} \\
\hline & $\lambda_{\max }^{(2)}$ & $\lambda_{\max }^{(1)}$ & $\lambda_{\max }^{(2)}$ & $\lambda_{\max }^{(1)}$ & $\lambda_{\max }^{(2)}$ & $\lambda_{\max }^{(1)}$ \\
\hline 4,7-diMe & 260 & 290 & 267 & 291 & 265 & 288 \\
\hline 6-Me & 261 & 300 & 268 & 301 & 264 & 300 \\
\hline $4-\mathrm{Br}$ & 263 & 295 & 271 & 297 & 268 & 296 \\
\hline 6-Cl & 258 & 305 & 263 & 301 & 259 & 300 \\
\hline $7-\mathrm{Cl}$ & 265 & 292 & 268 & 292 & 266 & 289 \\
\hline 6,7-diOH & 266 & 320 & 276 & 326 & 272 & 321 \\
\hline 7,8-diOH & 294 & 309 & 296 & 320 & 293 & 314 \\
\hline $6-\mathrm{NH}_{2}$ & 262 & 351 & 269 & 367 & 265 & 360 \\
\hline Chromone & 224 & 267 & 225 & 271 & 223 & 268 \\
\hline
\end{tabular}

The PCM and NCM excitations energies are calculated with a common TD-PBE0/6-311G(2d,2p)//B3LYP/6-311G(2d,2p) level of theory.

excitations energies calculated with a common TD-PBE0/ 6-311G(2d,2p)//B3LYP/6-311G(2d,2p) level of theory.

It turns out that: (i) the modification in the ground-state geometry has a slight impact on $\lambda_{\max }^{(1-2)}$ (see Table 1). With PCM, we got a $\sim 1 \mathrm{~nm}$ average difference between the $\lambda_{\max }$ in gas phase and in solvated phase (with the largest differences for the 4- $\mathrm{Br}$ molecule: +6 and $+3 \mathrm{~nm}$ bathoshift for $\lambda_{\max }^{(2)}$ and $\lambda_{\max }^{(1)}$, respectively). The same differences calculated with the NCM model are systematically less than $1 \mathrm{~nm}$. (ii) Compared to $\lambda_{\max }^{(1)}$, the $\lambda_{\max }^{(2)}$ are in general more affected by the direct solvent effects. The average difference between $\lambda_{\max }^{(2)}$ computed on the gas phase geometry with and without solvent effects (PCM) is systematically bathochromic $(+6 \mathrm{~nm})$, whereas for $\lambda_{\max }^{(1)}$ the magnitude is weaker with

Table 1

Solvation model effect on the calculated $\lambda_{\max }$ (in $\mathrm{nm}$ ) of coumarin derivatives and chromone

\begin{tabular}{|c|c|c|c|c|c|c|}
\hline \multirow[t]{2}{*}{ Substituents } & \multicolumn{2}{|c|}{ Gas UV } & \multicolumn{2}{|c|}{$\mathrm{PCM}(\mathrm{EtOH}) \mathrm{UV}$} & \multicolumn{2}{|c|}{$\mathrm{NCM}(\mathrm{EtOH}) \mathrm{UV}$} \\
\hline & $\lambda_{\max }^{(2)}$ & $\lambda_{\max }^{(1)}$ & $\lambda_{\max }^{(2)}$ & $\lambda_{\max }^{(1)}$ & $\lambda_{\max }^{(2)}$ & $\lambda_{\max }^{(1)}$ \\
\hline \multicolumn{7}{|l|}{ Gas geometry } \\
\hline 4,7-diMe & 263 & 292 & 271 & 293 & 265 & 288 \\
\hline 6-Me & 264 & 304 & 272 & 305 & 264 & 300 \\
\hline $4-\mathrm{Br}$ & 263 & 294 & 271 & 297 & 268 & 296 \\
\hline 7-Cl & 268 & 294 & 272 & 295 & 266 & 289 \\
\hline Chromone & 228 & 271 & 229 & 276 & 223 & 268 \\
\hline \multicolumn{7}{|c|}{ PCM geometry } \\
\hline 4,7-diMe & 264 & 293 & 272 & 294 & 265 & 288 \\
\hline 6-Me & 265 & 305 & 274 & 306 & 266 & 301 \\
\hline $4-\mathrm{Br}$ & 267 & 298 & 277 & 300 & 268 & 296 \\
\hline $7-\mathrm{Cl}$ & 268 & 295 & 273 & 296 & 266 & 290 \\
\hline Chromone & 228 & 271 & 229 & 276 & 223 & 268 \\
\hline \multicolumn{7}{|c|}{ NCM geometry } \\
\hline 4,7-diMe & 261 & 290 & 268 & 291 & 265 & 288 \\
\hline 6-Me & 262 & 301 & 269 & 301 & 265 & 300 \\
\hline $4-\mathrm{Br}$ & 264 & 295 & 272 & 297 & 268 & 295 \\
\hline 7-Cl & 265 & 293 & 269 & 293 & 266 & 289 \\
\hline Chromone & 224 & 267 & 225 & 270 & 223 & 268 \\
\hline
\end{tabular}

These results are related to the standard PCM and NCM procedure. 
an absolute average difference of only $\sim 2 \mathrm{~nm}$. For many derivatives, the displacements of the $\lambda_{\max }^{(1-2)}$ induced by NCM virtually appear in contradiction with PCM output. As an example, in the chromone case, the direct shift is $-3 \mathrm{~nm}$ for $\lambda_{\max }^{(1)}$ and of $-5 \mathrm{~nm}$ for $\lambda_{\max }^{(2)}$ for NCM, whereas the displacement induced by PCM is $+1 \mathrm{~nm}$ and $+5 \mathrm{~nm}$ for $\lambda_{\max }^{(1)}$ and $\lambda_{\max }^{(2)}$, respectively. The origin of this discrepancy is due to the slightly different basis sets used for PCM and NCM calculations, and one can check once a strictly identical set of basis functions is used (see Table 2) the sign of the PCM and NCM shifts became consistent.

Results in Table 2 show that the NCM values are systematically weaker than PCM results by $\sim 3 \mathrm{~nm}$. Since PCM solute-solvent non-electrostatic interactions are not taken into account in the TD calculations, the origin of discrepancies holds in the fact that the standard cavities used in each model are of different size (see Ref. [8] for more details). More precisely, NCM cavities volume and surface are systematically larger than in PCM by a factor of 1.11.2. As an example, for the 6- $\mathrm{NH}_{2}$ derivative, $\mathrm{NCM}$ returns a $228 \AA^{3}$ cavity volume ( $215 \AA^{2}$ surface) whereas PCM cavity parameters are of $191 \AA^{3}$ and $186 \AA^{2}$. However, the average difference between $\lambda_{\max }^{\mathrm{NCM}}$ and $\lambda_{\max }^{\mathrm{PCM}}$ remains very small.

\subsection{UV spectra evaluation}

\subsubsection{Confrontation of the models}

In Fig. 2 we provide a confrontation between NCM and PCM $\lambda_{\text {max }}^{(1-2)}$ listed in Table 3 whereas Fig. 3 depicts the correlation between NCM and PCM auxochromic shifts (the shifts induced by the side groups compared to the non substituted molecule). For $\lambda_{\max }^{(1)}$, Fig. 3 suggests that the $\mathrm{NCM} / \mathrm{PCM}$ divergences are related to systematic and quasi-constant discrepancies for coumarins and chromones. Indeed, the sign (batho/hypso) of the shift is always predicted in a coherent way by both models: the MAE is of $2 \mathrm{~nm}$ and only 2 shifts (4\%) present errors exceeding $10 \mathrm{~nm}$. Moreover, no deviation larger than $15 \mathrm{~nm}$ is observed. For $\lambda_{\max }^{(2)}$, the agreement between NCM and PCM shifts is not as good with a $6 \mathrm{~nm}$ MAE and the sign of the shift not always correctly predicted ( 5 shifts or $13 \%$ ). Fig. 2 and Table 3 point out that, for the chromone derivatives, the NCM $\lambda_{\max }^{(2)}$ are systematically weaker than PCM values, whereas the reverse behaviour is observed for the coumarin derivatives.

\subsubsection{Comparison with experiment}

The results of the theoretical evaluations are also compared with experimental measurements (obtained in ethanol) in Table 3. Since $\lambda_{\max }^{(1)}$ and $\lambda_{\max }^{(2)}$ are not localized in the same region of the electromagnetic spectrum and are related to different molecular orbitals (see Ref. [32] for more details), we treat them distinctly. In order to test the predictive abilities of the standard models, a SLR treatment of the TD-PBE0 results has been performed.
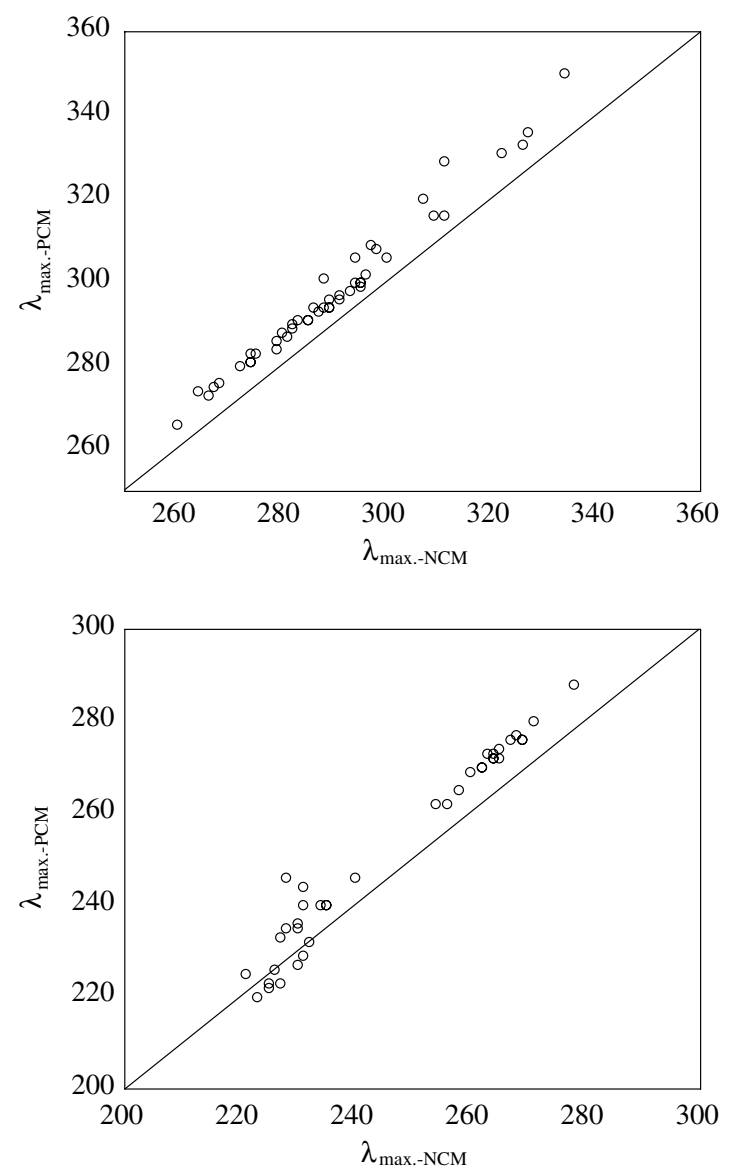

Fig. 2. Comparison of NCM and PCM $\lambda_{\max }^{(1)}$ (up) and $\lambda_{\max }^{(2)}$ (down) of absorption for the set of derivatives of Table 3 .

The calibration of the NCM $\lambda_{\max }$ leads to a set of two equations in such a way that experimental values (in $\mathrm{nm}$ ) are optimally reproduced. Theses equations are compared to their PCM counterparts

$\lambda_{\max -\operatorname{Exp}}^{(1)}=17.547+1.024 \lambda_{\max -\mathrm{NCM}}^{(1)}$

provides a $R^{2}$ of 0.8755 (adjusted $R^{2}$ of 0.8727 ). The related MAE is limited to $5 \mathrm{~nm}$ (or $0.06 \mathrm{eV}$ for the corresponding $\mathrm{eV}$ equation). Compared to the $25 \mathrm{~nm}(0.21 \mathrm{eV})$ non-fitted MAE, the SLR is obviously much more accurate. The SDR, which measures the magnitude of the accuracy for the design of new colorants, is $7 \mathrm{~nm}$, i.e., $\lambda_{\max -\operatorname{Exp}}^{(1)}=$ $\lambda_{\text {max-NCM }}^{\text {eq. }} \pm 7 \mathrm{~nm}( \pm 0.08 \mathrm{eV})$. This last result is in complete agreement with previous PCM-SLR investigations [32] for which

$\lambda_{\text {max-Exp }}^{(1)}=57.475+0.864 \lambda_{\text {max-PCM }}^{(1)}$

provides a $4 \mathrm{~nm}$ MAE $(0.05 \mathrm{eV})$, a reliability coefficient of 0.8902 (adjusted at 0.8878 , i.e., very similar to NCM one), and a SDR of $6 \mathrm{~nm}(0.08 \mathrm{eV})$. One has to note that the slope is very close to 1 for the NCM model. This shows that the NCM model almost perfectly predicts the exact variation of $\lambda_{\text {max }}^{(1)}$ whereas the PCM model seems to largely overestimate the variations as $\lambda$ increases. 
Table 3

$\lambda_{\max }^{(2)}-\lambda_{\max }^{(1)}$ (in $\left.\mathrm{nm}\right)$ provided by PCM(EtOH)TD-PBE0/6-311G+(2d,2p) and NCM(EtOH)TD-PBE0/6-311G(2d,2p) calculations, and SLR method, in ethanol

\begin{tabular}{|c|c|c|c|c|c|c|c|c|}
\hline \multirow[t]{3}{*}{ Compound } & \multicolumn{8}{|l|}{$\lambda_{\max }$} \\
\hline & $\mathrm{NCM}$ & PCM & NCM-Eq. (3) & NCM-Eq. (1) & PCM-Eq. (4) & PCM-Eq. (2) & Exp. & Ref. \\
\hline & $\lambda_{\max }^{(2)}-\lambda_{\max }^{(1)}$ & $\lambda_{\max }^{(2)}-\lambda_{\max }^{(1)}$ & $\lambda_{\max }^{(2)}$ & $\lambda_{\max }^{(1)}$ & $\lambda_{\max }^{(2)}$ & $\lambda_{\max }^{(1)}$ & $\lambda_{\max }^{(2)}-\lambda_{\max }^{(1)}$ & \\
\hline Coumarin & 264-289 & 272-294 & 273 & 313 & 275 & 312 & 274-311 & [29] \\
\hline 3-Me & $264-285$ & $273-291$ & 273 & 309 & 276 & 309 & $275-308$ & [29] \\
\hline 4-Me & $260-285$ & $269-291$ & 269 & 309 & 272 & 309 & $271-307$ & [29] \\
\hline 5-Me & $278-295$ & $288-300$ & 289 & 320 & 291 & 317 & $275-315$ & [28] \\
\hline 6-Me & $265-300$ & $274-306$ & 274 & 325 & 277 & 322 & $278-320$ & [28] \\
\hline 7-Me & $269-291$ & $276-297$ & 279 & 316 & 279 & 314 & $283-313$ & [28] \\
\hline 8-Me & $271-295$ & $280-299$ & 281 & 320 & 283 & 316 & $281-310$ & [28] \\
\hline 3,4-diMe & $264-286$ & $272-294$ & 273 & 310 & 275 & 312 & $273-308$ & [29] \\
\hline 4,6-diMe & $262-298$ & $270-302$ & 271 & 321 & 273 & 318 & $273-318$ & [29] \\
\hline 4,7-diMe & $265-288$ & $272-294$ & 274 & 312 & 275 & 312 & $278-314$ & [29] \\
\hline 4,8-diMe & $267-291$ & $276-296$ & 277 & 316 & 279 & 313 & $277-311$ & [29] \\
\hline 7-Me,4-OH & $258-281$ & $265-287$ & 267 & 305 & 268 & 305 & $245-304$ & [31] \\
\hline $3-\mathrm{OH}$ & $221-288$ & $225-301$ & 226 & 312 & 228 & 318 & $230-311$ & [28] \\
\hline $4-\mathrm{OH}$ & $254-279$ & $262-284$ & 262 & 303 & 265 & 303 & $268-303$ & [28] \\
\hline $5-\mathrm{OH}$ & $227-280$ & $233-288$ & 233 & 304 & 235 & 305 & $250-298$ & [28] \\
\hline $6-\mathrm{OH}$ & $263-327$ & $273-336$ & 272 & 352 & 276 & 348 & $280-345$ & [28] \\
\hline 7-OH & 269-294 & $240-306$ & 240 & 319 & 243 & 322 & $240-325$ & [30] \\
\hline 8-OH & $228-279$ & $246-286$ & 234 & 304 & 249 & 304 & $253-292$ & [28] \\
\hline 7,6-diOH & 322 & 331 & - & 347 & - & 343 & 348 & [28] \\
\hline 4-Me,5-OH & $230-275$ & $236-283$ & 236 & 299 & 239 & 302 & $250-294$ & [30] \\
\hline 4-Me,6-OH & $230-260$ & $235-266$ & 236 & 284 & 238 & 287 & $227-275$ & {$[30]$} \\
\hline 4-Me,7-NEt ${ }_{2}$ & $259-334$ & $244-350$ & 237 & 360 & 247 & 360 & $243-375$ & [28] \\
\hline $6-\mathrm{Me}, 4-\mathrm{OH}$ & 287 & 293 & - & 311 & - & 311 & 314 & [28] \\
\hline 3,6-diCl,4-MeO & 269-294 & $276-300$ & 279 & 319 & 279 & 317 & $280-320$ & [28] \\
\hline $7-\mathrm{Cl}$ & 289 & 296 & - & 313 & - & 313 & 313 & {$[28]$} \\
\hline $4-\mathrm{Br}$ & $268-295$ & $277-300$ & 278 & 320 & 280 & 317 & $277-318$ & [28] \\
\hline 4-MeO,3-Me & $262-282$ & $270-289$ & 271 & 306 & 273 & 307 & $272-310$ & [28] \\
\hline 4,6-diMeO & $256-311$ & $262-316$ & 265 & 336 & 265 & 331 & $270-327$ & [28] \\
\hline $5-\mathrm{MeO}$ & 282 & 290 & - & 306 & - & 308 & 298 & [28] \\
\hline 5-MeO,7-OH & $235-307$ & $240-320$ & 242 & 332 & 243 & 334 & $247-330$ & {$[28]$} \\
\hline 7-MeO,8-OH & 293 & 298 & - & 318 & - & 315 & 325 & {$[28]$} \\
\hline $7-\mathrm{MeO}$ & $269-298$ & $240-308$ & 242 & 323 & 243 & 324 & $242-325$ & [28] \\
\hline 7-MeO,4-OH,5-Me & $221-283$ & $240-291$ & 307 & 237 & 243 & 309 & 242-309 & [28] \\
\hline 7-MeO,6-OH & $240-326$ & $246-333$ & 247 & 351 & 249 & 345 & $257-351$ & [28] \\
\hline $4-\mathrm{NMe}_{2}$ & 289 & 294 & - & 313 & - & 312 & 306 & [28] \\
\hline $\mathrm{C} 440$ & 311 & 329 & - & 336 & - & 342 & 354 & {$[31]$} \\
\hline Chromone & 268 & 276 & - & 292 & - & 296 & 298 & [29] \\
\hline 2-Me & $225-267$ & $222-275$ & 231 & 291 & 225 & 295 & $225-295$ & [29] \\
\hline 2,3-diMe & $230-274$ & $227-281$ & 236 & 298 & 229 & 300 & $225-299$ & [29] \\
\hline 2,6-diMe & $226-274$ & $226-283$ & 232 & 298 & 228 & 302 & $225-303$ & [29] \\
\hline 2,7-diMe & $225-266$ & $223-273$ & 231 & 290 & 225 & 293 & $225-294$ & [29] \\
\hline 2,8-diMe & $228-272$ & $235-280$ & 234 & 296 & 238 & 299 & $225-299$ & [29] \\
\hline 3-Me & $227-274$ & $223-281$ & 233 & 298 & 225 & 300 & $225-304$ & [29] \\
\hline $5-\mathrm{OH}, 2-\mathrm{Me}$ & 231-309 & $229-316$ & 237 & 334 & 232 & 331 & $226-326$ & [30] \\
\hline 6-OH,2-Me & $232-297$ & 232-309 & 238 & 322 & 234 & 324 & $226-326$ & [30] \\
\hline 7-OH,2-Me & $223-264$ & $220-274$ & 228 & 288 & 223 & 294 & $226-302$ & [30] \\
\hline
\end{tabular}

All geometries are obtained at the B3LYP/6-311G(2d,2p) level.

For the second peak,

$\lambda_{\text {max-Exp }}^{(2)}=-16.277+1.097 \lambda_{\max -\mathrm{NCM}}^{(2)}$

has a lower adjusted $R^{2}(0.8471)$, provides a MAE limited to $6 \mathrm{~nm}$ or $0.13 \mathrm{eV}$, and allows a prediction with a $\pm 9 \mathrm{~nm}$ or $0.18 \mathrm{eV}$ error. Compared to the PCM regression [32],

$\lambda_{\text {max-Exp }}^{(2)}=1.379+1.005 \lambda_{\text {max-PCM }}^{(2)}$ for which we calculate a $4 \mathrm{~nm} / 0.09 \mathrm{eV}$ MAE, a $6 \mathrm{~nm} /$ $0.13 \mathrm{eV}$ SDR and a adjusted $R^{2}$ of 0.9143 , the NCMSLR model provides a bit less reliable and less accurate predictions for $\lambda_{\max }^{(2)}$.

While for the NCM model, the slopes are very close to 1 for both peaks, the intercepts are very different and of opposite reverse sign. The variation is about $-33 \mathrm{~nm}$. This clearly indicates that NCM underestimates the first 

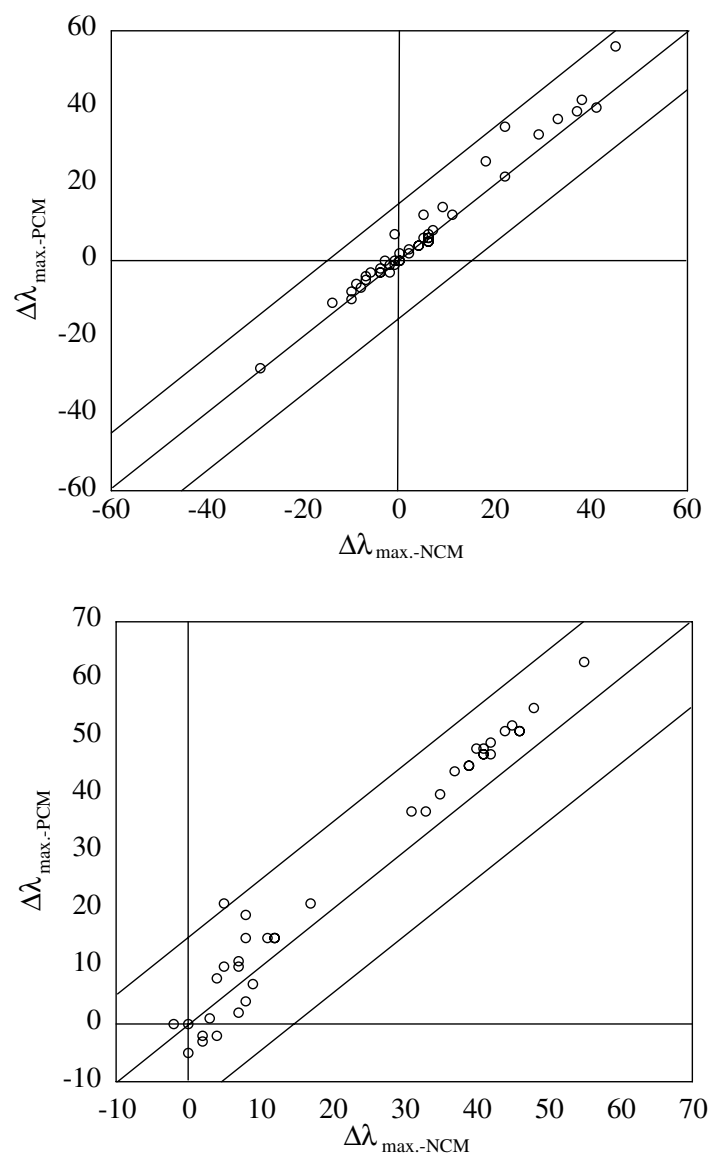

Fig. 3. Comparison between NCM and PCM $\lambda_{\max }^{(1)}$ (up) and $\lambda_{\max }^{(2)}$ (down) auxochromic shifts (in $\mathrm{nm}$ ) for substituted forms of pyranone dye. The central line indicates a perfect match whereas the two sidelines are borders for $\pm 15 \mathrm{~nm}$ discrepancies.<smiles>O=c1cc(C(F)(F)F)c2cc3c4c(c2o1)CCCN4CCC3</smiles>

Fig. 4. Sketch of C540 A dyes. wavelength but overshoots the second one. This is certainly related to the different natures of the two excited states. This can also be seen for the PCM model for which the intercept varies by $-56 \mathrm{~nm}$.

All these results point out the relative importance of the additional diffuse functions used in the PCM formalism, that are absent in our standard NCM model. While the impact of diffuse functions on the $\lambda_{\max }^{(1)}$ prediction is weak (we calculate a NCM-PCM average discrepancy of $2 \mathrm{~nm}$ ), their presence remains essential to correctly predict $\lambda_{\max }^{(2)}$ of pyranones. The huge sensitivity of $\lambda_{\max }^{(2)}$ to diffuse functions can be explained by the fact that, compared to $\lambda_{\max }^{(1)}$, the charge transfer from the benzenic cycle to the pyranone moiety is larger. Fig. 5 depicts the density redistribution related to $\lambda_{\max }^{(1)}$ and $\lambda_{\max }^{(2)}$. This figure shows that the charge transfert is much larger for the second excitation. The intercept of Eq. (3) could certainly be reduced to values closer to zero with the help of diffuse functions.

\subsubsection{Model validation}

In order to confirm the validity of our predictive models, external set of five dyes have been made up by several $-\mathrm{OH}$, $-\mathrm{MeO}$, as well as combined substitution patterns (see Table 4). We have added C540A (Fig. 4) as this compound is widely used as laser dyes. It turns out that the SLRMAE is of $8 \mathrm{~nm}(0.085 \mathrm{eV})$ and of $7 \mathrm{~nm}(0.125 \mathrm{eV})$ for $\lambda_{\max }^{(1)}$ and $\lambda_{\max }^{(2)}$, respectively. This is in complete agreement with the SDR of Eqs. (1) and (3). Furthermore, we have maximum theory/experiment discrepancies limited to

Table 4

Comparison between the experimental and theoretical $\lambda_{\max }^{(2)}-\lambda_{\max }^{(1)}$ of coumarin derivatives

\begin{tabular}{llllll}
\hline Compound & PBE0 & Eq. (3)- $\lambda_{\max }^{(2)}$ & Eq. (1)- $\lambda_{\max }^{(1)}$ & Exp & Ref. \\
\hline 7-Me,6-NO ${ }_{2}$ & $268-309$ & 278 & 334 & $264-316$ & {$[27]$} \\
5,7-diMeO & $237-286$ & 244 & 310 & $242-312$ & {$[28]$} \\
4-MeO,7-OH,5-Me & $231-283$ & 237 & 307 & $235-305$ & {$[28]$} \\
6,7,8-triMeO & $234-329$ & 240 & 354 & $232-346$ & {$[31]$} \\
C540A & 384 & - & 411 & 422 & {$[31]$} \\
\hline
\end{tabular}

All values are in $\mathrm{nm}$ and calculated via the NCM standard formalism.
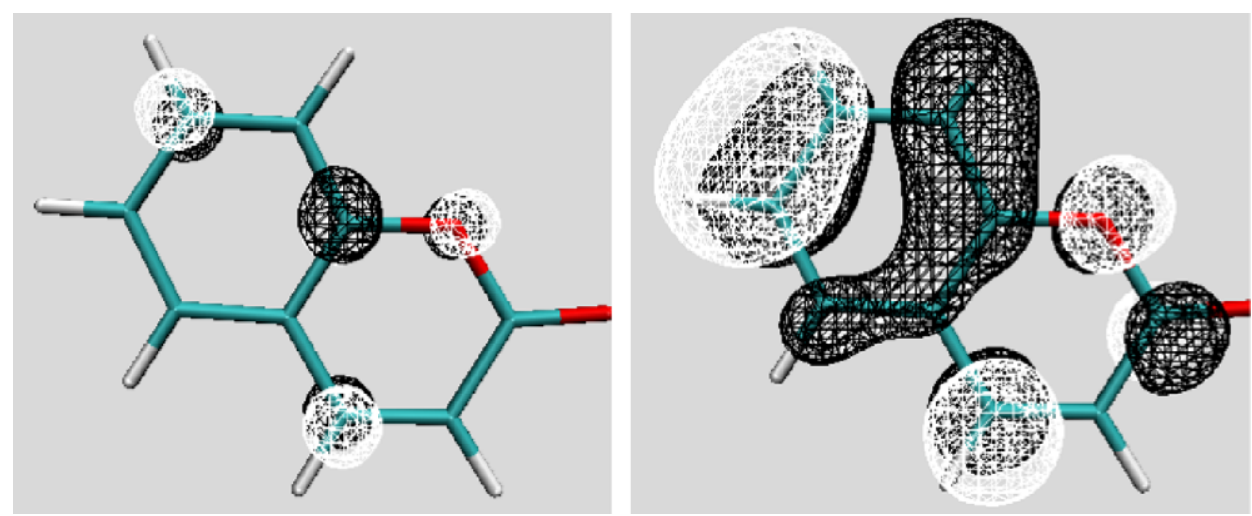

Fig. 5. Comparison between $\lambda_{\max }^{(1)}$ (left) and $\lambda_{\max }^{(2)}$ (right) density redistribution for the coumarin dye. In this figure, the isodensity is scaled at 0.1 electron. 
$18 \mathrm{~nm}$ or $0.211 \mathrm{eV}$ for $\lambda_{\max }^{(1)}$, and $14 \mathrm{~nm}$ or $0.236 \mathrm{eV}$ for $\lambda_{\max }^{(2)}$. The only case for which deviations exceeding $15 \mathrm{~nm}$ have been found is attributed to the 7-Me,6- $\mathrm{NO}_{2}$-coumarin, a molecule presenting a significant charge transfer involving the nitro group. For this type of molecule, it is well known that conventional (TD)-DFT overshoots the charge transfer and underestimates the related excitation energies [33]. In the case of the 5,7-diMeO and 4-MeO,7-OH,5-Me coumarin, we have a perfect match between theoretical and experimental $\lambda_{\max }^{(1)}$ and $\lambda_{\max }^{(2)}$ (a $2 \mathrm{~nm}$ difference).

\section{Conclusions}

We have reported a methodological study of the liquidphase UV spectra of pyranone derivatives. The $\lambda_{\max }$ resulting from two SCRF formalisms (PCM and NCM) have been compared and confronted to experimental data. All calculations have been carried out at the NCM-TDPBE0/ 6-311G(2d,2p)//NCM-B3LYP/6-311G(2d,2p) and the PCMTDPBE0/6-311+G(2d,2p)//PCM-B3LYP/6-311G(2d,2p) levels of theory.

For both models, the relative weight of the direct and indirect contributions has been investigated. It turns out that: (i) the modification of the ground-state geometry has a slight impact on $\lambda_{\max }^{(1-2)}$ (ii) Compared to $\lambda_{\max }^{(1)}, \lambda_{\max }^{(2)}$ are in general more affected by the direct solvent effects. Moreover, the average differences between $\lambda_{\max }^{\mathrm{NCM}}$ and $\lambda_{\max }^{\mathrm{PCM}}$ remain weak, suggesting that the choice of the cavity size has a minor impact on the UV spectra.

For the NCM treatment of substituted pyranones, the required accuracy for the design of molecules has been reached: we calculate an accuracy on the predictive data of $7 \mathrm{~nm} / 0.08 \mathrm{eV}$ for $\lambda_{\max -\operatorname{Exp}}^{(1)}$ and $9 \mathrm{~nm} / 0.18 \mathrm{eV}$ for $\lambda_{\max -\operatorname{Exp}}^{(2)}$. Compared to PCM values, the NCM formalism provides $\lambda_{\max }^{(1)}$ prediction with an equivalent accuracy and reliability. For $\lambda_{\max }^{(2)}$, the lack of additional diffuse functions (which are present in the standard PCM procedure) in the NCM procedure does not authorize, a this stage, a perfect description of the second excitation. Although the NCM model leads to much faster TD-DFT calculations than PCM (see Ref. [8]), especially as the size of the system increases, the divergence of the wave function caused by diffuse orbitals presents a severe limitation that will be corrected in a future release.

\section{Acknowledgements}

J.P. acknowledges the FRIA (Belgian "Fonds pour la formation à la Recherche dans l'Industrie et dans l'Agriculture") for his PhD grant. D.J. and E.A.P. thank the Belgian National Fund for their respective Research Associate positions. Part of the calculations have been performed on the Interuniversity Scientific Computing Facility (ISCF), installed at the Facultés Universitaires Notre-Dame de la Paix (Namur, Belgium), for which the authors grate- fully acknowledge the financial support of the FNRSFRFC and the "Loterie Nationale" for the convention number 2.4578.02 and of the FUNDP. The authors thank the CGRI (Commissariat Général aux Relations Internationales de la Communauté Française de Belgique) for its financial support. The authors thank the CNRS-CGRI-FNRS collaboration for its financial support (agreement \#18195).

\section{References}

[1] C.J. Cramer, D.G. Truhlar, Chem. Rev. 99 (1999) 2161.

[2] J. Tomasi, M. Persico, Chem. Rev. 94 (1994) 2027.

[3] J. Tomasi, B. Mennucci, R. Cammi, Chem. Rev. 105 (2005) 2999.

[4] J. Hirsh, J.E. Daelen, D.R. Anderson, L. Poller, H. Bussey, J. Ansell, D. Deykin, CHEST 115 (2001) 4708.

[5] R.M. Christie, Colour Chemistry, Royal Society of Chemistry, Cambridge, UK, 2001.

[6] H. Zollinger, Color Chemistry. Synthese, Properties, and Applications of Organic Dyes and Pigments, Wiley-VCH, Zürich, 2003.

[7] D. Jacquemin, E.A. Perpète, G. Scalmani, M.J. Frisch, X. Assfeld, I. Ciofini, C. Adamo, J. Chem. Phys. 125 (2006) 164324.

[8] J. Preat, P.-F. Loos, X. Assfeld, D. Jacquemin, E.A. Perpète, Int. J. Quantum Chem. 107 (2007) 574.

[9] M. Cossi, V. Barone, J. Chem. Phys. 115 (2001) 4708.

[10] E. Cancès, B. Mennucci, J. Tomasi, J. Chem. Phys. 107 (1997) 3032.

[11] B. Mennucci, R. Cammi, J. Tomasi, J. Chem. Phys. 110 (1999) 6858.

[12] M. Cossi, V. Barone, B. Mennucci, J. Tomasi, Chem. Phys. Lett. 286 (1998) 253.

[13] B. Mennucci, J. Tomasi, J. Chem. Phys. 106 (1997) 5151.

[14] B. Mennucci, E. Cancès, J. Tomasi, J. Phys. Chem. B 101 (1997) 10506.

[15] J. Tomasi, B. Mennucci, E. Cancès, J. Mol. Struct. (Theochem) 464 (1999) 211.

[16] R. McWeeny, Methods of Molecular Quantum Mechanics, Academic Press, London, UK, 1992.

[17] D. Rinaldi, A. Bouchy, J.-L. Rivail, V.J. Dillet, Chem. Phys. 102 (2004) 2343.

[18] D. Rinaldi, A. Bouchy, J.-L. Rivail, Theor. Chem. Acc. 116 (2006) 664.

[19] M.J. Frisch, G.W. Trucks, H.B. Schlegel et al., GAUSSIAN 03 Revision C 02, Gaussian, Inc., Pittsburg, PA, 2003.

[20] D. Rinaldi, R.R. Pappalardo, SCRFPAC: Quantum Chemistry Program Exchange, Indian University, Bloomington, IN, 1992, program no. 622 .

[21] A.D. Becke, J. Chem. Phys. 98 (1993) 5648.

[22] J.P. Perdew, Phys. Rev. B 33 (1986) 8822.

[23] J.P. Perdew, K. Burke, Y. Wang, Phys. Rev. B 54 (1996) 16533.

[24] C. Adamo, V. Barone, J. Chem. Phys. 110 (1999) 6158.

[25] P. Dagnelie, Statistique Théorique et Appliquée, Tome 1 \& 2; De Boeck and Larcier: Bruxelles, 1998.

[26] J. Pollard, A Handbook of Numerical and Statistical Techniques, Cambridge University Press, Cambridge, UK, 1979.

[27] K.V. Masrani, H.S. Rama, S.L. Bafna, J. Appl. Chem. Biotechnol. 24 (1974) 311.

[28] A.G. Gonzalez, J.T. Barroso, Z.D. Jorge, F. Rodriguez Luiz, Revista de la Real Academia de Ciencias Exactas, Fisicas y Naturales de Madrid (ISSN: 0034-0596) 75 (1981) 811.

[29] B.K. Gnaguly, P. Bagchi, J. Org. Chem. 21 (1956) 1415.

[30] S. Kalyanmay, P. Bagchi, J. Org. Chem. 24 (1959) 316.

[31] The Aldrich Handbook of Fine Chemicals and Laboratory Equipment Aldrich, Bornem, 2003-2004.

[32] J. Preat, D. Jacquemin, V. Wathelet, J.-M. André, E.A. Perpète, J. Phys. Chem. A 110 (2006) 8144.

[33] A. Dreuw, M. Head-Gordon, J. Am. Chem. Soc. 126 (2004) 4007. 